\title{
A POSSIBILIDADE DE UTILIZAÇÃO DO SISTEMA WMS PARA MELHORIA DA GESTÃO DE ARMAZENAGEM: O CASO DE UMA EMPRESA DO RAMO DE CONSTRUÇÃO DA ZONA DA MATA MINEIRA
}

\author{
THE POSSIBILITY OF USING THE WMS SYSTEM TO IMPROVE STORAGE MANAGEMENT: THE \\ CASE OF A COMPANY IN THE CONSTRUCTION BRANCH OF THE MATA MINEIRA ZONE
}

\section{Jessica Taveira da Rocha ${ }^{1}$, Luiz Alberto Teixeira Oliveira ${ }^{2}$, Mário César Fialho de Oliveira ${ }^{3}$, Sanderson Rocha de Abreu ${ }^{4}, \&$ Patricia Werneck Silva de Oliveira ${ }^{5}$ \\ 12345 Faculdades Integradas de Cataguases - FIC/UNIS. \\ $1 *$ jessica.taveira@alunos.unis.edu.br ${ }^{2}$ luiz.teixeira@alunos.unis.edu.br ${ }^{3}$ mario.oliveira@ professor.unis.edu.br \\ ${ }^{4}$ sanderson.abreu@ unis.edu.br ${ }^{5}$ patricia.oliveira@professor.unis.edu.br}

\section{ARTIGO INFO.}

Recebido em: 20.08.2021

Aprovado em: 27.10.2021

Disponibilizado em: 01.12.2021

\section{Palavras-chave:}

Armazenagem; estoque; WMS; melhoria do processo; e-commerce.

KEYWORDS:

Storage; inventory; WMS; process improvement; ecommerce.

\section{*Autor Correspondente: Rocha, J. T., da. \\ RESUMO}

A necessidade de expansão das atividades e o ganho de vantagem competitiva é uma realidade no atual cenário mercadológico. Nesse contexto, os processos internos da organização repercutem em seu desempenho no mercado. Assim, a preocupação com a gestão da armazenagem se mostra de grande relevância, uma vez que essa possui o poder de garantir o atendimento das novas demandas. $\mathrm{O}$ presente artigo trata-se de pesquisa aplicada, qualitativa, de caráter descritivo, com desenvolvimento de estudo de caso, tendo como propósito estudar e identificar os problemas que afetam o sistema de gestão de armazenagem e estoque do Centro de Distribuição da rede de lojas de uma empresa de revenda de materiais de construção. O objetivo é analisar a gestão de armazenagem a fim de diagnosticar problemas existentes, e indicar possíveis ganhos com adoção de um sistema Warehouse Management System (WMS). Através de entrevistas com colaboradores, supervisores dos setores, visitas ao local e relatórios com dados analíticos. Enquanto resultados, a identificação de diversos problemas envolvendo a Gestão da Armazenagem da organização, concluindo que a mesma não conta com um sistema informatizado para tal serviço e que seu estoque não possui endereçamento dos produtos, o que acarreta dificuldades para separação de pedidos, realização de inventário, e acaba por comprometer a acuracidade de estoque da mesma. Como forma de proposição de melhoria para a atual situação da armazenagem e melhor planejamento do estoque, foi realizada a classificação da Curva $\mathrm{ABC}$, e, foi demonstrada as vantagens, sugerida a aquisição e implantação de sistema WMS, que se mostrou capaz de atenuar as principais problemática que atualmente acomete a organização.

\begin{abstract}
The need to expand activities and gain competitive advantage is a reality in the current market scenario. In this context, the organization's internal processes affect its performance in the market. Thus, the concern with storage management is of great relevance, as it has the power to guarantee that new demands are met. This article is an applied, qualitative, descriptive research, with the development of a case study, with the purpose of studying and identifying the problems that affect the storage and stock management system of the Distribution Center of the chain of stores. a building materials dealership. The objective is to analyze the warehouse management in order to diagnose existing problems, and indicate possible gains with the adoption of a Warehouse Management System (WMS) system. Through interviews with employees, sector supervisors, site visits and reports with analytical data. As a result, the identification of several problems involving the organization's Storage Management, concluding that it does not have a computerized system for such service and that its stock does not have product addressability, which causes difficulties in order picking, carrying out inventory, and ends up compromising its stock accuracy. As a way of proposing improvement for the current situation of storage and better stock planning, the classification of the $A B C$ curve was carried out, and the advantages were demonstrated, the acquisition and implementation of a WMS system was suggested, which proved capable of mitigating the main problem that currently affects the organization.
\end{abstract}




\section{INTRODUÇÃO}

A Globalização e o crescente avanço das tecnologias têm feito com que as organizações busquem alternativas e inovações que as auxiliem em seus resultados, por meio de aprimoramento de seus serviços e alcance um maior número de clientes. Com o cenário mercadológico cada vez mais acirrado, a competitividade de comercialização de produtos causa uma disputa entre as empresas, que para obter vantagem competitiva deve buscar meios de sobressair a concorrência.

Com o habitual uso da internet, e a fim de alavancar as vendas, ganhar maior visibilidade e alcançar um número maior de clientes, as empresas varejistas têm expandido seus negócios além dos estabelecimentos físicos, passando atuar no comércio virtual. O e-commerce, como é chamado esse tipo de negócio, proporciona a empresa a vantagem de disposição de seus produtos na rede mundial de computadores, servindo para captação de novos clientes e aumento no faturamento. A nível do cliente, o consumidor também se beneficia deste modelo de negócio, de forma a experimentar uma maior variedade de produtos e fornecedores, comparação de preço, formas variadas de pagamento, preços competitivos e serviços pós-venda.

No entanto, para se inserir no e-commerce os varejistas físicos precisam se adequar ao modelo de negócio, estruturar seu serviço para o novo tipo de atendimento para que possa atender de forma satisfatória e assim alcançar seus objetivos. A implementação de novas tecnologias tem sido grande aliado nessa busca por vantagem competitiva, de maneira a atuar com facilitador na comunicação, tanto com fornecedores quanto com clientes, trazendo mudanças nos processos de produção, logística e estoque.

Nesse sentido, aprimorar o processo de armazenagem é de muita importância para os resultados da organização, uma vez que os sistemas de armazenagem e gestão de estoque são responsáveis por garantir a disponibilidade de recursos para o atendimento das demandas surgidas. Ainda enquanto argumento justificador, tem-se que o controle adequado dos armazéns traz eficiência ao processo e ao serviço. Assim, é relevante a análise dos sistemas e processos de gestão de armazenagem, com identificação de falhas, levantamento de suas necessidades e a busca por alternativas que possam favorecer um controle eficiente de estoque e armazenagem. Segundo Rodrigues, Fernandes, Formigoni, Monteiro, \& Campos (2011, p.1), "a gestão do armazém sempre representou um desafio para as organizações, de maneira que, manter o estoque de forma acessível e com prazos de atendimento reduzidos passou a significar um dos fatores de competência para as empresas".

Neste contexto, o presente artigo tem objetivo geral realizar uma análise da gestão de armazenagem e estoque do Centro de Distribuição da rede de lojas de uma empresa de revenda de materiais de construção. O mesmo foi ampliado devido as novas demandas trazidas pelas atividades no e-commerce, com o intuito de diagnosticar problemas existentes, e indicar possíveis ganhos com adoção de um sistema Warehouse Management System (WMS). Como objetivos específicos a pesquisa buscará: (i) analisar o processo e ferramentas de armazenagem realizadas pela empresa, diagnosticando suas formas de registro, gestão de dados, estrutura e layout de armazenagem; (ii) Classificar e analisar a movimentação de estoque, utilizando a

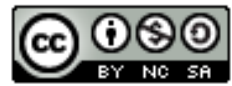


curva ABC; (iii) Identificar possíveis falhas e levantar possíveis soluções; (iv) Apontar as vantagens oferecidas pelas tecnologias WMS no controle e monitoração da armazenagem.

\section{REVISÃO DE LITERATURA}

Nesta seção serão apresentadas algumas contribuições teóricas acerca da necessidade e os benefícios das organizações em manter uma eficaz gestão da armazenagem utilizando o conceito da curva $\mathrm{ABC}$, apontando para as novas tendências tecnológicas dos Sistemas de Informação capazes de auxiliar nesta função, em especial o (WMS), apontando suas funcionalidade e vantagens de implantação. E, ainda, a abordagem do crescente uso da internet e sua implicação no comércio eletrônico e a definição do conceito de Marketplace.

A Curva ABC é uma metodologia baseada no teorema do economista Vilfredo Pareto, o qual em seu estudo observou que uma pequena parcela da população $(20 \%)$ detinha a maior parte da riqueza (80\%) (Facchini, Silva, \& Leite, 2019). Dessa teoria surge a ferramenta da Curva ABC eficiente no auxílio na administração do estoque. Segundo Santos e Lubiana (2017, p. 62), “a curva $\mathrm{ABC}$ é uma importante ferramenta gerencial que tem por função analisar e classificar os produtos que requerem uma atenção especial do gestor". A classificação consiste na definição dos itens de maior relevância em relação ao faturamento enquanto A, B e C.

\subsection{Gestão da armazenagem}

O conceito de gestão da armazenagem não é algo recente, uma vez que a água e mantimentos eram armazenados e estocados pelas civilizações antigas, com o propósito de garantir a sobrevivência nos períodos de escassez. Com o tempo, esse processo passou por uma grande evolução, até alcançar os modos atuais onde a gestão da armazenagem tem grande importância na organização, gerarando valor para o cliente final.(Ballou, 1993)

Atualmente, a armazenagem tem sido alvo de grandes transformações. Tais transformações estão atreladas ao uso e adoção de sistemas de informação, de sistemas automáticos de movimentação e separação de pedidos, bem como o uso de modernos equipamentos e estrutura de armazenagem (Soriano, 2013).

Para Ballou (2006), a armazenagem pode contribuir em quatro aspectos da organização: (i) reduzindo custos com transporte e produção, (ii) coordenando a oferta e demanda, (iii) colaborando no processo de comercialização (iv) assessorando no processo de produção.

Rodrigues (2001, p.36) traz um conceito que bem elucida armazenagem:

Armazenagem é definido como a gestão de estoque de mercadorias, englobando localização, definição de área utilizada, layout, docas de separação e processos no armazém. (Rodrigues, 2001,p. 36)

Em consonância com esse conceito (Banzato, Carillo, Banzato, Moura, \& Rego, 2010) dispõem que a principal função da armazenagem é gerir o espaço disponível que maneira em que o armazém seja organizado de forma racional, o que contribuiria na redução ou melhor utilização dos tempos das atividades operacionais ali realizadas, o que só é possível por meio de eficiente fluxo de materiais e informação. 
Ballou (2006) afirma, ainda, que no referente as atividades operacionais a gestão de armazenagem é responsável pela estocagem de produtos e manuseio de matérias, envolvendo as questões referentes a adoção layout adequando, escolha e manutenção de equipamentos e controle das atividades e processos inerentes à armazenagem.

No atual cenário de competitividade em que vivemos é indispensável para a organização manter um eficiente controle de seu estoque (Favaretto, 2012). A importância sobre o controle dos processos operacionais são destacados por Soriano (2013, p.34):

Para maior eficiência operacional, realizar registros e monitoramento de atividades é de muita importância. Com tais informações, quando analisadas, observando históricos, com objetivo de propor melhorias, auxiliar na tomada de decisões, ações corretivas e preventivas no processo. (Soriano, 2013, p.34)

Para Paoleschi (2014), a armazenagem pode ser entendida enquanto um processo que de alta agregação de valor na cadeia de suprimentos, e, que manter um eficaz controle da movimentação e estocagem dos produtos é algo capaz de proporcionar um melhor atendimento aos clientes. O autor defende a ideia do planejamento racional dos armazéns, como aprimoramento do processo.

\subsection{O uso do Sistema WMS na gestão de armazenagem}

O Warehouse Management System, popularmente conhecido por sistema WMS, é um sistema de gestão, que funciona por meio de Software capaz de auxiliar nas atividades de armazenagem usando da gestão de informação para atingir a eficiências nos processos e tarefas da armazenagem, com possibilidade de efetivo controle e precisão dos níveis de estoque e inventário (Banzato, 2010).

Na concepção de Kuroda (2017), o WMS é um sistema promovido pela TI (Tecnologia da Informação) o qual é capaz de contribuir positivamente para o processo de armazenagem das organizações. Para Junior e Spejorim (2012) a implantação do referido sistema proporciona diversos ganhos diretos, ligados à eficiência da armazenagem, como eficiência na alocação de materiais e movimentação de produtos; otimização dos espaços e trajetos; conhecimento da real situação de estoque, com possibilidade de rastreamento; minimização das perdas e ajustes de inventário. Os autores apontam ainda que para além dos ganhos diretos a implantação do sistema, pode promover ganhos indiretos que estão relacionados à ergonomia e segurança das atividades, assim como a organização do ambiente de trabalho.

Em mesmo sentido, Rosa (2011) entende que o WMS é capaz de proporcionar as organizações o aumento da produtividade; o aumento o nível de segurança do controle da armazenagem, e, ainda, obter dados e informações mais precisas sobre real situação do estoque.

Segundo Soriano (2013), o WMS é uma ferramenta de alto nível de complexidade, no qual suas funções são adaptáveis às características e área de atuação da empresa. O autor elenca enquanto possibilidades de funções do sistema: programar entrada de pedidos; portaria e gerenciador de pátios; planejar e alocar recursos; pré-receber produtos; receber produtos; rstocar produtos; reparar produtos; fazer inventário; controlar contenedores; controlar desempenho operacional; priorizar tarefas urgentes; integrar intercâmbio eletrônico de dados; inspecionar e controlar a 
Citação (APA): Rocha, J. T., da, Oliveira, L. A. T., Oliveira, M. C, F., de, Abreu, S. R., de, \& Oliveira, P. W. S., de. (2021). A possibilidade de utilização do sistema WMS para melhoria da gestão de armazenagem: o caso de uma empresa do ramo de construção da zona da mata mineira, 7(5), 166-182.

qualidade; rastrear produtos; integrar Radio Frequency Identification (RFID); atualizar online o saldo em estoque; controlar o Cross-docking; formar kits; preparar documentos de expedição; programar a manutenção de veículos; realizar simulações; gerenciar devoluções; agregar valor aos serviços; e calcular o número de embalagens para despacho.

Com a possibilidade de informações mais exatas sobre o processo de armazenagem e situação de estoque, fica assegurado a organização a melhor alocação de recursos para o melhor atendimento de seus objetivos e a redução dos custos com a armazenagem, uma vez que seus processos deverão ser pautados na real eficiência, com a devida organização e planejamento (Junior \& Spejorim, 2012).

Para o melhor funcionamento e atendimento às necessidades do processo operacional de armazenagem, o sistema WMS necessita de tecnologia suporte para auxiliar nas atividades de armazenagem. São apontados como recursos para esse fim os coletores de código de barras, antenas receptoras, código de barras e RFID. Por meio do código de barra é possível obter diversas informações sobre o produto como fabricante, lote e data de validade, por exemplo, e também podem ser obtidas informações referentes ao seu endereçamento do produto no estoque. Para isso é necessário a realização de leitura e registro da movimentação dos produtos, a ser realizadas pelos coletores. Outra possibilidade é o uso de RFID, que com um auxílio de uma antena de captura de rádio frequência, detecta e identifica online o posicionamento do produto (Soriano, 2013).

Não obstante aos benefícios apontados para implantação do sistema WMS, essa ainda que com seus potenciais ganhos pode encontrar dificuldades para sua implantação como: a demanda de grande investimento inicial; a falta de conhecimento da ferramenta pelos colaboradores que irão operá-la; necessidade de treinamento da equipe; resistência dos colaboradores às mudanças; e a necessidade de mudança e/ou adaptação do processo operacional (Banzato et al., 2010).

\subsection{Viabilização do e-commerce e markatplace}

O comércio eletrônico, também chamado de e-commerce, pode ser entendido como um mercado que se usa da internet como canal de comercialização ligando fornecedores e consumidores, possibilitando a venda de produtos, distribuição, negociação e prestação de serviços (Kubota \& Milani, 2011). Trata-se de uma nova proposição de negócio em que consumidores podem comparar preços, escolher fornecedores e forma de pagamento, tudo de forma digital, não necessitando deslocar até a loja física (Teixeira, 2015).

A B2W - Companhia Digital, sociedade anônima inscrita, com sede no Rio de Janeiro - RJ. Através de sua plataforma digital a companhia combina vendas diretas, marketplace e serviços digitas, por meio dos seus sites Americanas.com. Submarino, Shoptime e SouBarato. São oferecidos um vasto surtimento de produtos, em mais de 40 categorias e cerca de 20 milhões de itens (B2W, 2021).

De acordo com a plataforma B2W (2021), o e-commerce encontra-se em contínua ampliação. Tal crescimento é fundamentado pelos seguintes fatores: maior utilização da Internet, aumento do hábito de compras online entre os usuários de Internet, crescimento de banda larga e sortimento limitado em lojas tradicionais. 
De acordo como as informações da plataforma B2W (2021), atualmente, o Brasil tem percebido um grande avanço do número de acessos e usuários da internet. Esse acesso é facilitado, principalmente pelo uso dos smartphones, que proporcionam ao usuário a possibilidade de portar, durante todo o dia, aparelho capaz de acessar a internet. A introdução da internet no cotidiano das pessoas, com presença cada vez mais efetiva, não apenas para entretenimento, mas como ferramenta de trabalho e concretização de serviços, como por exemplo, a transmissão do imposto de renda e internet banking, é um fator que justifica o aumento do comércio eletrônico, que com popularização da internet tende a se tornar um hábito na vida das pessoas. Logicamente, essa evolução é acompanhada pela evolução tecnológica, e, a evolução da própria internet, por meio do crescimento da banda larga, cujos acessos também se mostram crescentes na população brasileira. O comércio eletrônico disponibiliza ao cliente uma variedade muito maior que os varejistas físico brasileiro. O pouco sortimento do mercado físico está relacionado a dificuldade de espaços nas prateleiras e suprimento de lojas filiais. Neste sentido o varejista online tem a vantagem de não ter limitação física de exposição de seus produtos e nem tão pouco a necessidade de replicar o estoque em suas lojas, podendo apresentar grande sortimento de produtos (B2W, 2021)

Em 2020 houve um crescimento de 40\%, em relação ao ano anterior, do número de consumidores do comercio eletrônico, alcançando a marca de 41 milhões de consumidores. Com isso houve no primeiro semestre de 2020 o recorde de faturamento neste tipo de comércio com a marca de $\mathrm{R} \$ 38,8$ bilhões. Percebe-se um aumento nas transações no período da pandemia. Em específico, as operações tipo marketplace BRICKS AND CLICKS, entendidos como as organizações que atendem no varejo tradicionalmente físico que entraram no comercio online, cresce $61 \%$ em faturamento, comparado com o mesmo período do ano anterior (Ebit, 2020)

O comércio eletrônico atende bem uma necessidade da população atual que, por vezes não disponibiliza de tempo para realizar pesquisas e compras no mercado físico. Aquele passou a ser uma extensão do comércio convencional, que em um ambiente digital possibilita a realização de transações comerciais, como compra, venda, prestação de serviço, por meio de aparelhos e programas de informática (Teixeira, 2015).

Uma forma de e-commerce em expansão é o chamado marketplace, um site de $e$-commerce comparado a um shopping virtual, no qual são ofertados serviços e produtos de diversos vendedores (Euromonitor, 2018). Franco, Maia, \& Souza Filho (2020) descreve o marketplace, enquanto um mercado em que compradores e vendedores se encontram e realizam negócios virtualmente. Esse mercado tem como principais funções: "tornar possível o encontro de compradores e vendedores; facilitar a troca de informações, bens, serviços e pagamentos relacionados à transação; e proporcionar uma infraestrutura que possibilite o funcionamento eficiente desse mercado" (Franco et al., 2020, p.2).

Assim como no varejo físico, o marketplace possui grandes empresas líderes em seu segmento, que vendem seus produtos e abrem espaço para outras empresas negociarem seus produtos e serviços, via web. (Franco et al., 2020). Na definição do SEBRAE (2017, p.2)“(...) marketplace online é uma plataforma colaborativa, também denominada shopping virtual, onde um conjunto 
Citação (APA): Rocha, J. T., da, Oliveira, L. A. T., Oliveira, M. C, F., de, Abreu, S. R., de, \& Oliveira, P. W. S., de. (2021). A possibilidade de utilização do sistema WMS para melhoria da gestão de armazenagem: o caso de uma empresa do ramo de construção da zona da mata mineira, 7(5), 166-182.

de empresas ofertam produtos e serviços no mesmo endereço, na internet. $\mathrm{O}$ processo de vendas, geralmente, fica sob responsabilidade do organizador (...)."

São apontadas pelo SEBRAE as seguintes vantagens competitivas do marketplace:

Permite usufruir do sistema de pagamento integrado;

Possibilita à novas empresas on-line se tornarem conhecidas;

Permite oferecer aos clientes fretes com condições diferenciadas, devido aos parceiros especialistas em logística;

Atrai alto fluxo de visitantes;

Permite usufruir da estrutura tecnológica que engloba usabilidade, segurança e formas de pagamento diversas (SEBRAE, 2017, p.7).

São apontadas ainda como vantagem desse modelo de comércio a possibilidade da ampliação do portfólio de artigos para venda, com isso um aumento de receita operacional. O varejista agregado vale-se da imagem de visibilidade do e-commerce hospedeiro, de modo que atrela os seus produtos a grandes plataformas as quais já possuem credibilidade no mercado, sem a necessidade de investimento na construção de uma plataforma própria (Euromonitor, 2018).

Por outro lado, a estratégia apresenta traz alguns desafios operacionais como a dependência e possível perda de qualidade nos serviços de entrega e pós-venda, uma vez que estes são definidos pelo hospedeiro. Enquanto desvantagens também são apresentadas questões como a cobrança de taxas de comissionamento e a impossibilidade de aplicação de estratégias próprias (Ebit, 2018).

\section{METODOLOGIA}

Para a realização do trabalho foi utilizada metodologia de pesquisa aplicada, qualitativa, de caráter descritivo, com desenvolvimento de estudo de caso, tendo como propósito estudar e identificar os problemas que afetam o sistema de gestão de armazenagem em uma empresa de revenda de materiais de construção, com sede em Cataguases-MG.

Através do uso de ferramentas e métodos de engenharia propor medidas e soluções para esses problemas. De princípio, usou-se de levantamento bibliográfico, para embasamento teórico da pesquisa, e, em segundo momento foi realizada a pesquisa de campo, através da coleta de dados, informações acerca da gestão de estoque e armazenagem devido necessidade de aprimoramento dos sistemas de armazenagem, causado pela ampliação de estoque, motivada pelo impacto e os resultados da sua inserção no $e$-commerce

Para a coleta de dados foram utilizadas as técnicas de entrevistas, análise documentos e visita em loco. Para tanto, foram realizadas entrevistas semiestruturadas com supervisor responsável pela armazenagem dos produtos no centro de distribuição da empresa e com o colaborador responsável pela expedição dos pedidos do marketplace da empresa. As entrevistas foram pautadas nas questões pertinentes ao sistema de armazenagem da empresa, bem como os problemas enfrentados no setor, principalmente após a ampliação do estoque, devido a adesão da mesma ao marketplace, por meio da plataforma B2W. O outro instrumento usado para a coleta de dados foi a análise documental de relatórios fornecidos pela empresa que demonstraram as movimentações das vendas e faturamento relativos ao Marketplace. O estudo

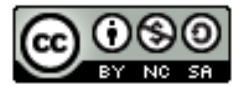


destes documentos proporcionou uma noção da quantidade do contingente de vendas e mais um a série de informações relevantes ao estudo de caso.

Também para a coleta de dados, foi realizada visita em loco para verificação real das condições e modo de armazenagem, bem como o gerenciamento e controle do estoque realizado pela organização.

Com todos dados e informações em mãos, através das visitas realizadas criou-se estratégias, quais ferramentas poderiam ser utilizadas para propor melhorias, resolver os problemas mencionados para alcançar o objetivo de ter uma operação mais eficiente e estoque com maior acuracidade.

A ferramenta Warehouse Management System (WMS) foi considerada que teria maior eficiência diante o cenário da empresa, em todos aspectos seriam supridas as necessidades de cada setor, tal ferramenta foi apresentada e analisada custo de implantação, cada benefício que conseguiria alcançar de acordo com benefícios citados de diversos autores.

\section{ESTUDO DE CASO}

Como objetivos específicos, a pesquisa buscará:

(i) analisar o processo e ferramentas de armazenagem realizadas pela empresa, diagnosticando suas formas de registro, gestão de dados, estrutura e layout de armazenagem;

(ii) Classificar e analisar a movimentação de estoque utilizando a curva $\mathrm{ABC}$;

(iii) Identificar possíveis falhas e levantar possíveis soluções;

(iv) Apontar as vantagens oferecidas pelas tecnologias WMS no controle e monitoração da armazenagem.

\subsection{Caracterização da empresa pesquisada}

A empresa em estudo é uma das maiores redes de revenda de materiais de construção de Minas Gerais. Com sede no município de Cataguases-MG, a empresa possui atualmente 11 lojas, distribuídas nas cidades de Cataguases, Juiz de Fora, Leopoldina, Além Paraíba, Muriaé. A organização conta atualmente com 250 colaboradores, atuantes nos seus setores administrativo, estoque, entrega e vendas.

Consolidada pelas vendas em suas lojas físicas, afim de ampliar sua atuação no mercado, crescer em competitividade e seguindo as novas tendências de consumo, a empresa iniciou-se na modalidade de vendas online no mês de Agosto de 2019. Para tanto foi escolhida a plataformas de marketplace B2W para iniciar esse trabalho.

No início, toda operação do setor de vendas no marketplace, utilizava estrutura física já existente da empresa, funcionários e software, sofrendo apenas pequenas alterações nos processos e adaptações necessárias. Com a evolução de mix de produtos atualizados nos sites, alguns meses em execução as vendas tiveram um aumento considerável, principalmente após a pandemia, elevando quantidade de vendas, reputação na plataforma, maior competitividade no mercado, maior credibilidade e poder de compras nos fornecedores. 
Citação (APA): Rocha, J. T., da, Oliveira, L. A. T., Oliveira, M. C, F., de, Abreu, S. R., de, \& Oliveira, P. W. S., de. (2021). A possibilidade de utilização do sistema WMS para melhoria da gestão de armazenagem: o caso de uma empresa do ramo de construção da zona da mata mineira, 7(5), 166-182.

A evolução das vendas pode ser percebida no Gráfico 1, de acordo com relatórios fornecidos, que apontam o número de pedidos realizados por meio da plataforma no seu primeiro ano de atuação.

Gráfico 1. Contingente de pedidos do Marketplace em seu primeiro ano de atuação

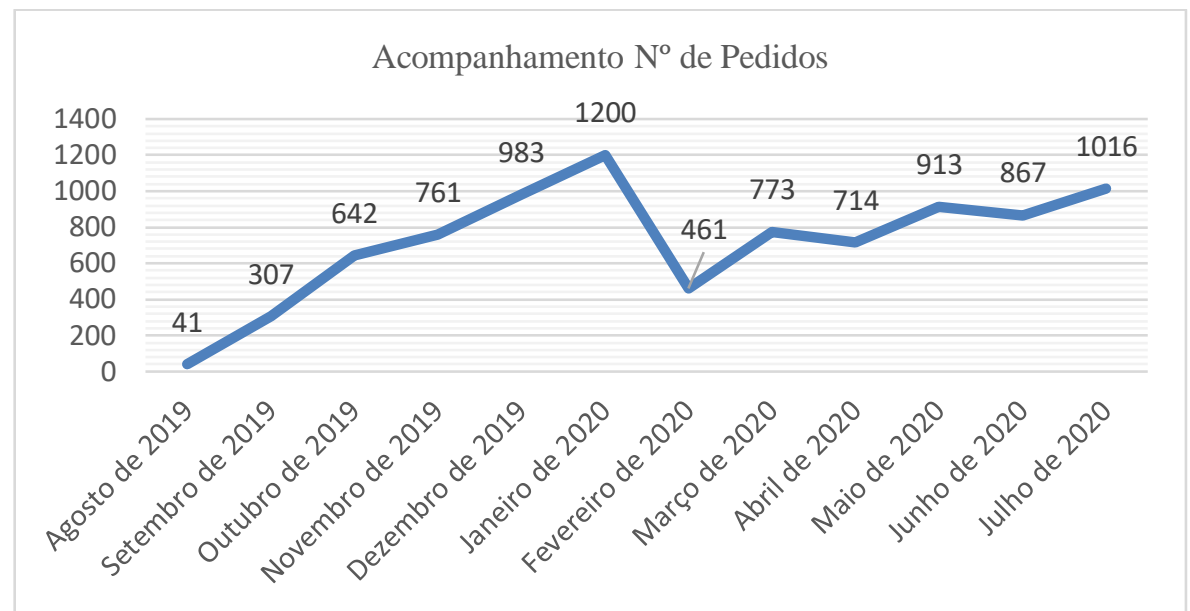

Fonte: Autores (2021).

Através dos relatórios, foi notado o aumento das vendas pelo $e$-commerce, consequentemente promoveu uma evolução no faturamento mensal da organização, o que segue demostrado no Gráfico 2, referente ao segundo semestre do ano de 2020.

Gráfico 2. Faturamento do segundo Semestre de 2020

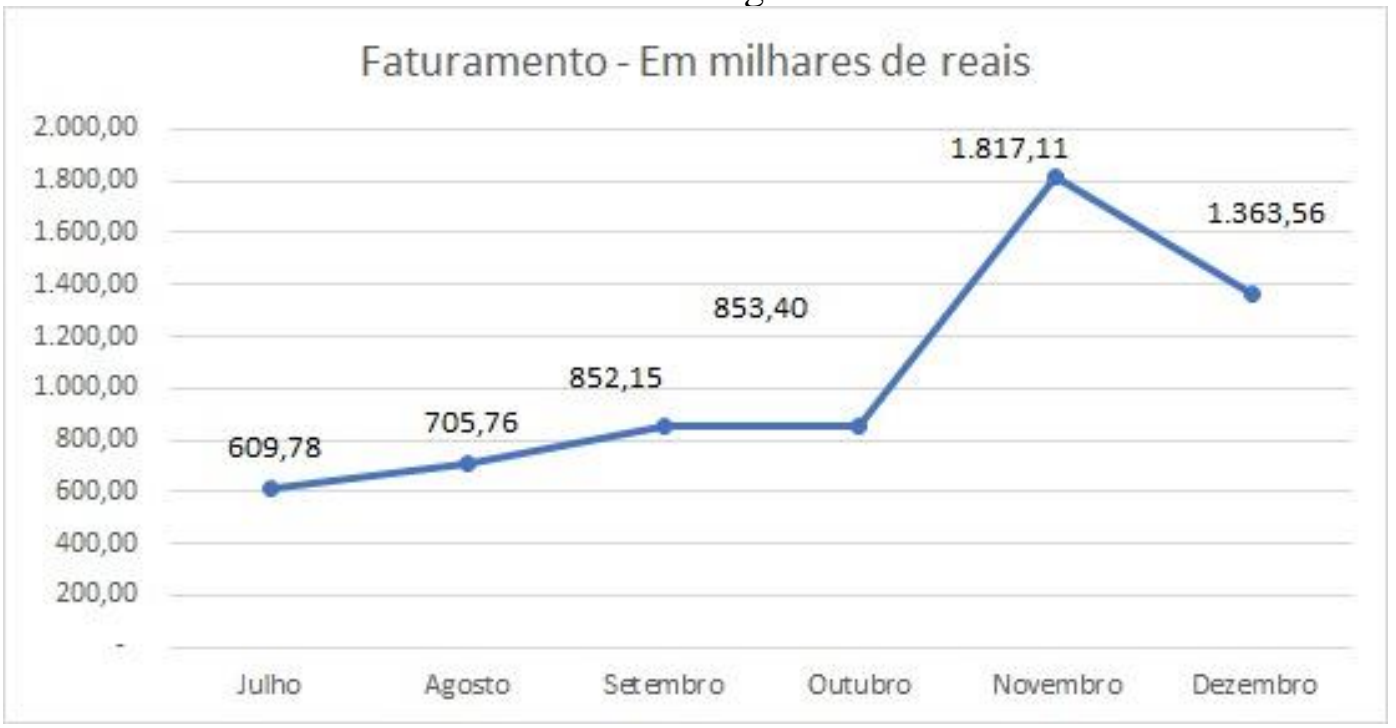

Fonte: Autores (2021).

$\mathrm{Na}$ entrevista pessoal com o supervisor de planejamento e controle de estoque, após análise dos relatórios, foi informado que com a notória expansão dos negócios, houve a necessidade de novo espaço físico para armazenamento, separação e controle do estoque dos produtos vendidos no marketplace. Também se fez necessário o aumento no número de funcionários, computadores e equipamentos. Para o atendimento da nova demanda foi implantado um novo

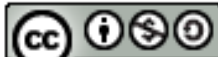


processo de separação, conferência e despacho de mercadorias para se adaptar às regras da plataforma e ter bom nível de prestação de serviço aos clientes para evitar ocorrências.

Após a separação dos pedidos, é acionado o serviço de coleta, realizado por uma transportadora parceira da plataforma B2W, que encaminha os mesmos aos seus centros de distribuição, de acordo com a localização final, e fica responsável pela entrega ao cliente.

\subsection{A situação da gestão de armazenagem da Organização}

Conforme entrevista concedida pelo supervisor de planejamento e controle de estoque da empresa, visita realizada em loco e acesso a dados e relatórios do setor de processo de armazenagem da empresa, se tornou possível descrição da atual situação e gestão de armazenagem e estoque da mesma.

A empresa tem processos a serem seguidos desde o recebimento até a expedição, para ter o controle de toda cadeia de suprimentos, conta com uma divisão interna por setores e conta com uma pessoa responsável por cada setor, para melhor controle dos produtos. Mas não há nenhum sistema informatizado utilizado par esse fim. O processo de recebimento dos produtos até sua alocação do estoque segue demonstrado na Figura 1, em que as etapas definidas buscam o melhor controle e confiabilidade.

\subsubsection{Recebimento de mercadorias}

Figura 1. Procedimento de recebimento de mercadorias

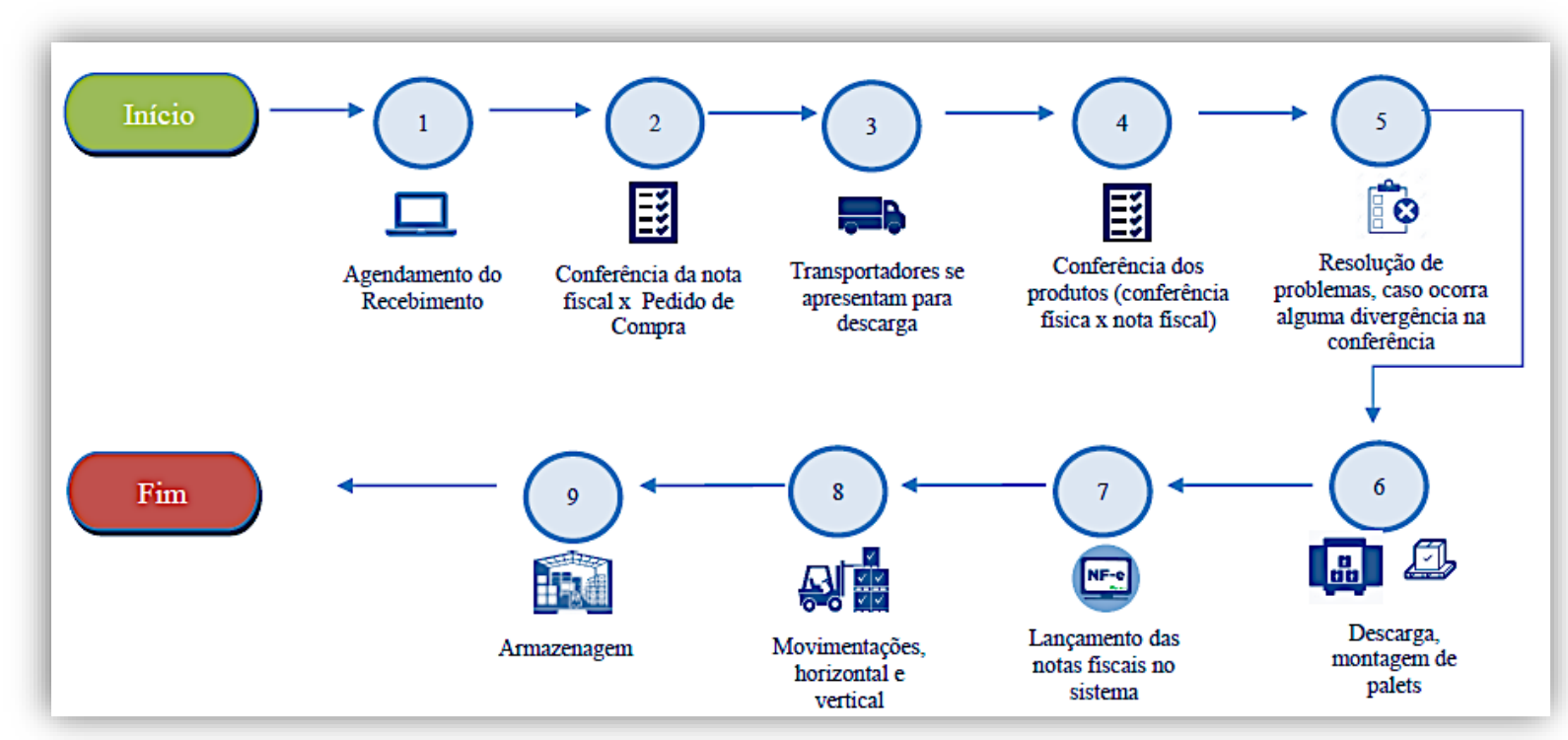

Fonte: Autores (2021).

O local de armazenamento dos produtos comercializados no marketplace foi criado como complemento, um imóvel alugado interligado lateralmente com o galpão do CD (Centro de Distribuição) principal da empresa, que tem vários setores de diversos tipos de produtos, responsável por abastecer 11 filiais, receber, armazenar e transportar a maior parte dos pedidos vendidos nas lojas físicas. 
Cada setor tem um tipo específico de armazenagem, de acordo com cada tipo de produto e fornecedor, em armazenamento vertical e horizontal, dispostos em prateleiras, porta pallets, suporte para ferragens e pilhas de pallets blocados um sobre o outro.

Para a operação e alocação no estoque conta-se com ferramentas como 3 empilhadeiras, 5 paleteiras, 5 pranchas e 8 carrinhos de cargas para movimentação interna.

Não existe endereçamento feito para controlar todos setores e produtos, há algumas ruas e prateleiras identificadas em alguns setores, mas sem uso total de tal identificação, o que dificulta muito ao procurar produtos para separação de pedidos e inventários de estoque em determinados setores.

O setor de "marketplace" é muito afetado em questão de armazenamento, pois fica distante do recebimento e porta pallets que ficam os produtos após conferidos, sem identificação alguma, no alto, assim dificultando saber onde está o produto desejado para separação de pedidos por exemplo, sendo necessário descer muitos pallets utilizando uma empilhadeira para tentar achar o produto desejado. No caso específico desse setor, além da eficiência esperada em para o atendimento de pedidos, este tem tempo de separação e expedição definidos por regras da Plataforma em que atuam, de maneira que necessitam otimizar o tempo para atender tempo hábil os pedidos realizados. Abaixo, na Figura 2, segue o processo de separação no setor "marketplace" onde ficam armazenados os produtos comercializados na plataforma.

\subsubsection{Separação de pedidos do Marketplace}

Figura 2. Processo de separação de pedidos do Marketplace

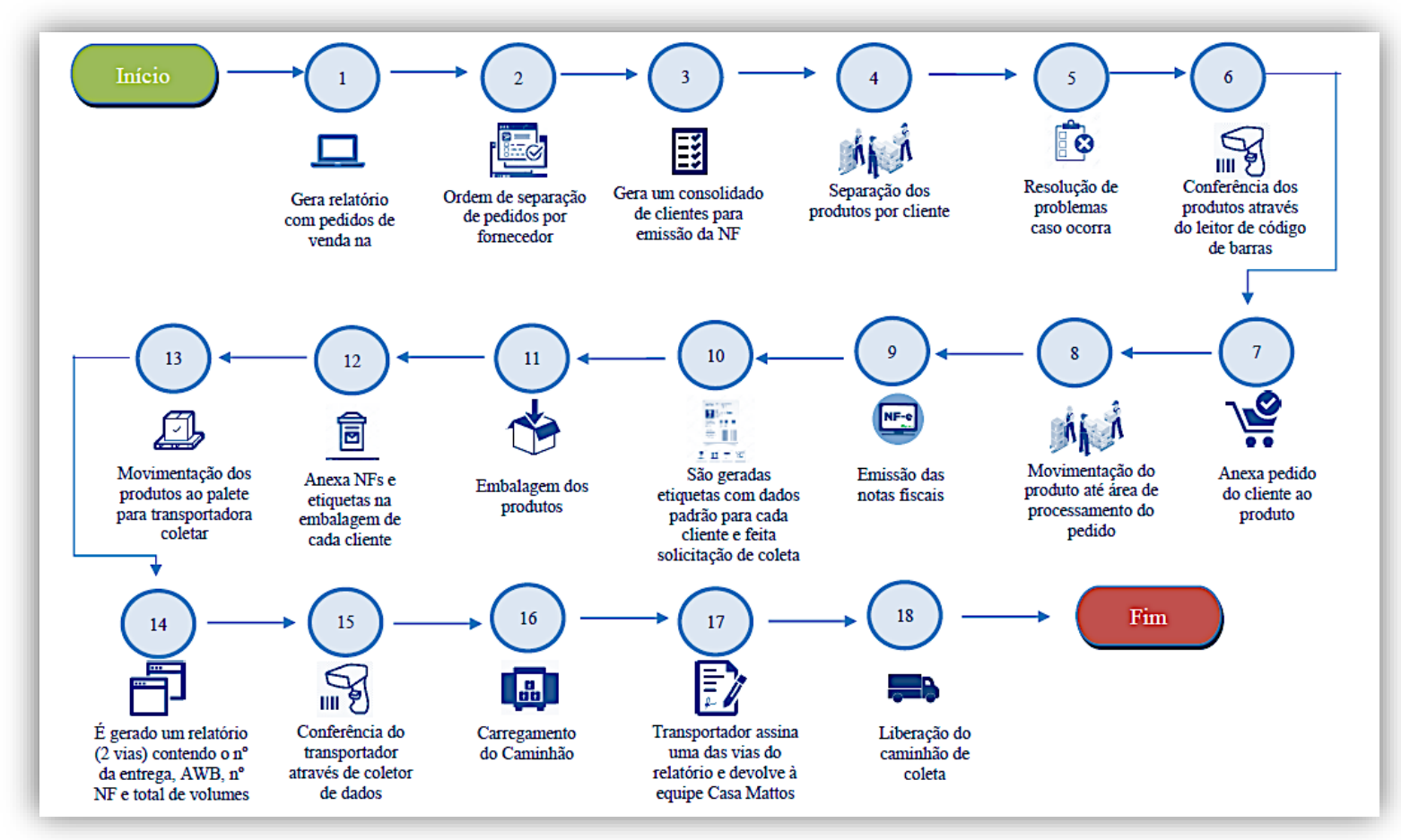

Fonte: Autores (2021).

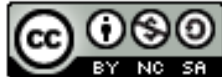


A empresa possui o setor de Planejamento e Controle de Estoque - PCE, responsável por programar e controlar inventários de estoque, fazer a gestão de estoque de todas filiais e CDs acordo com orientações e objetivos estabelecidos pela diretoria, assim criando indicadores, dados a serem acompanhados e analisados para criar estratégias, tomada de decisões e indicar ações comerciais

A tomada de decisão acerca da realização de inventário, de maneira a definir o que deve ser inventariado, utiliza como parâmetro os seguintes tópicos:

1. Produtos de fornecedores com maior giro e valor de estoque;

2. Produtos que estão parados a muito tempo (itens da curva D e E), para tomar ação comercial;

3. Produtos que estão no relatório de itens não encontrados em cada setor;

4. Solicitação de algum setor caso identificado alguma irregularidade;

5. Fornecedor completo de acordo com demanda.

O procedimento de inventário na empresa tem métodos e critérios definidos de acordo com o ilustrado na Figura 3.

\subsubsection{Inventário de estoque}

Figura 3. Procedimento para inventário de estoque

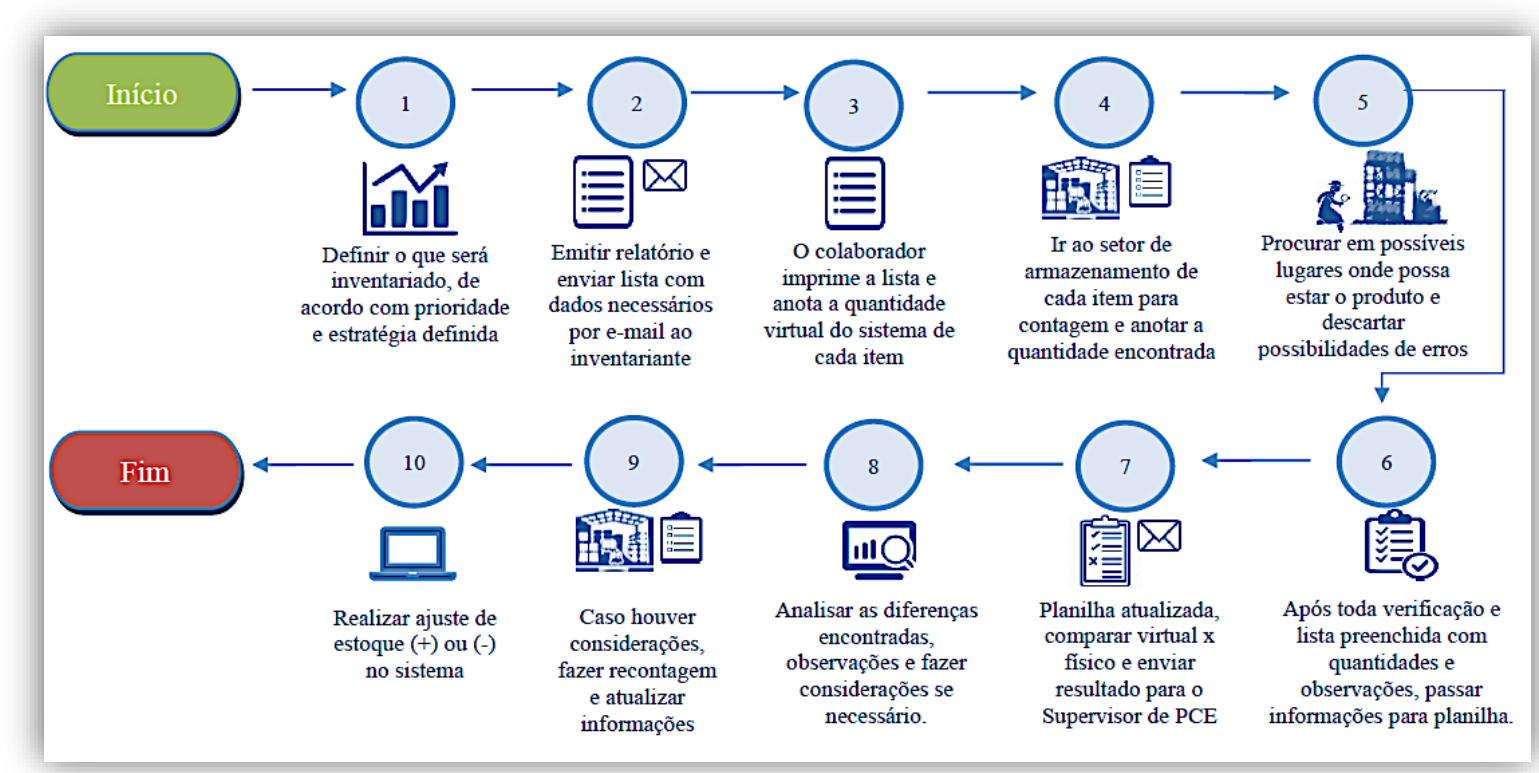

Fonte: Autores (2021)

Vale ressaltar que não há uma periodicidade definida para realização dos inventários, esses são definidos a partir da necessidade e tomada de decisão do setor responsável.

Como bem elucidado a Empresa tem procedimentos e métodos definidos para gestão da armazenagem, mas não obstante os esforços empreendidos, principalmente devido a expansão dos negócios após a inserção no comércio virtual, e consequentemente de seu setor de estoque, é percebido uma necessidade de aprimoramento e otimização do setor para atendimento satisfatório de sua demanda. 


\section{RESULTADOS E DISCUSSÃO}

O estudo de caso permitiu observar aspectos importantes sobre a gestão e forma de armazenagem desenvolvida pela empresa estudada. O primeiro aspecto observado é a falta de endereçamento e padronização da armazenagem. Sem a identificação ou catalogação dos endereços das mercadorias no estoque a procura de produtos é manual e sem quaisquer parâmetros de localização. O que, certamente faz aumentar a demora pelo êxito da ação. De certo, como os setores possuem colaboradores específicos, a rotina diária leva ao conhecimento empírico da localização de determinados produtos, o que na prática agiliza um pouco a busca por produtos. Mas isso não é uma prática confiável, principalmente para uma organização em ascendência que pretende continuar evoluindo no mercado, pois em caso de mudança ou substituição de desse colaborador o novato não terá esse conhecimento e demorará indeterminado período para concluir a tarefa.

Um segundo aspecto está relacionado a ausência de controle atualizado e efetivo do estoque, uma vez que não há sistema informatizado para tanto e que os inventários não são realizados com periodicidade definida, ficando a cargo da tomada de decisão do setor de Planejamento e Controle de Estoque.

O terceiro aspecto está atrelado ao crescimento das atividades da empresa após sua inserção no mercado virtual. Há de se considerar que para uma empresa evoluir no mercado ela também precisa evoluir em seus processos internos, de forma a atender de forma satisfatória a demanda gerada. O notório crescimento das atividades, demonstrado pelos dados obtidos apontam para readequação da empresa para essa nova realidade. Desse aspecto, ainda denota, a necessidade expressiva de tratar de forma diferenciada a armazenagem os produtos do setor de markatplace, uma vez que há uma determinação de tempo para a separação e expedição dos pedidos, em atendimento as normas da plataforma em estão associados.

Evidencia-se que da realidade depreendida são encontrados alguns problemas na operacionalização de estoque e gestão da armazenagem da empresa. Segue abaixo elencados no Quadro 1 o apontamento das falhas recorrentes na rotina do estoque da organização, bem como suas eventuais causas e possíveis soluções:

Quadro 1. Principais problemas ocorridos no cotidiano do estoque

\begin{tabular}{|c|c|c|}
\hline $\begin{array}{c}\text { Identificação das } \\
\text { Falhas Recorrentes }\end{array}$ & Prováveis Causa & Possíveis Soluções \\
\hline $\begin{array}{c}\text { Demora na separação } \\
\text { dos pedidos }\end{array}$ & $\begin{array}{c}\text { Não conhecimento de onde o } \\
\text { mesmo se encontra }\end{array}$ & $\begin{array}{c}\text { Treinamento da equipe e suporte de informação } \\
\text { a cerca da localização dos produtos }\end{array}$ \\
\hline $\begin{array}{c}\text { Dificuldade de } \\
\text { localizar produtos }\end{array}$ & Falta de endereçamento & $\begin{array}{c}\text { Adoção de sistema de endereçamento das } \\
\text { mercadorias }\end{array}$ \\
\hline $\begin{array}{c}\text { Dificuldade de } \\
\text { alocação das } \\
\text { mercadorias em seu } \\
\text { respectivos setores por } \\
\text { falta de espaço }\end{array}$ & $\begin{array}{c}\text { Falta de planejamento do } \\
\text { ambiente e definição } \\
\text { específica de layout }\end{array}$ & $\begin{array}{c}\text { Melhor controle das mercadorias recebidas e } \\
\text { planejamento realizado de acordo com suas } \\
\text { especificações volumétricas para alocação em } \\
\text { layout definido. }\end{array}$ \\
\hline $\begin{array}{c}\text { Falta de acuidade de } \\
\text { estoque }\end{array}$ & $\begin{array}{c}\text { Deficiência ou não } \\
\text { regularidade dos inventários }\end{array}$ & $\begin{array}{c}\text { Adoção de sistematização da gestão de estoque } \\
\text { e inventários periódicos }\end{array}$ \\
\hline $\begin{array}{c}\text { Dificuldade de } \\
\text { planejamento }\end{array}$ & Devido a falta de acuidade & Classificação por meio da Curva ABC \\
\hline
\end{tabular}

Fonte: Autores (2021) 
As principais falhas encontradas, se bem observadas são oriundas de problemas maiores que são a falta de endereçamento e um sistema automatizado para dar agilidade e confiabilidade nas ações e informações.

Sem dúvida, para qualquer melhoria é imprescindível treinamento da equipe para que os colaboradores possam exercer suas atividades de forma técnica e padronizada, evitando o desencontro de informações e métodos, que devem ser bem definidos pela organização, assim como forma auxiliar na potencialização do tempo das atividades.

Sobre a questão de planejamento de estoque, é recomendado a utilização da classificação dos itens por meio da curva ABC. De posse dos dados coletados foi então realizada a classificação dos itens de estoque do setor marketplace conforme a Curva ABC. Considerando a representatividade no faturamento da empresa os itens foram em três níveis de importância, sendo curva A $80 \%$, curva B $15 \%$ e curva C $5 \%$ do valor faturado, como segue demostrado no Quadro 2 e Gráfico 3.

Quadro 2. Classificação ABC

\begin{tabular}{|c|c|c|c|rr|}
\hline \multicolumn{5}{|c|}{ Classificação em Relação ao Valor de Venda } \\
\hline Curva & Qtd Itens & Causa & Efeito & \multicolumn{2}{c|}{ Venda } \\
\hline A & 102 & $25 \%$ & $80 \%$ & $\mathrm{R} \$$ & $4.960 .307,20$ \\
\hline B & 117 & $28 \%$ & $15 \%$ & $\mathrm{R} \$$ & $928.395,02$ \\
\hline C & 197 & $47 \%$ & $5 \%$ & $\mathrm{R} \$$ & $313.076,05$ \\
\hline Total & $\mathbf{4 1 6}$ & $\mathbf{1 0 0 \%}$ & $\mathbf{1 0 0 \%}$ & $\mathbf{R} \$$ & $\mathbf{6 . 2 0 1 . 7 7 8 , 2 7}$ \\
\hline
\end{tabular}

Fonte: Autores (2021)

Gráfico 3. Curva ABC

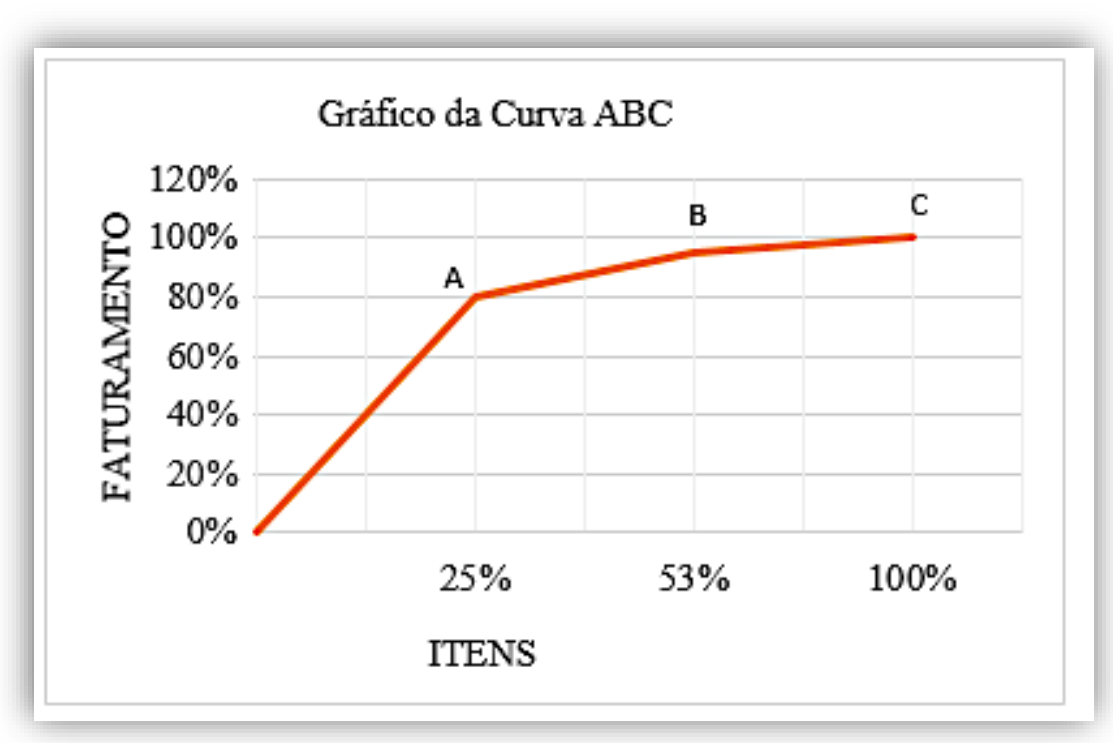

Fonte: Autores (2021)

Diante da perceptível evolução da empresa nos últimos meses, certamente impulsionada pela adesão à modalidade de comercio eletrônico e dada sua fragilidade na gestão de armazenagem, devido a falta de automação e sistemas para tal gestão, o que faz ocorrer as principais falhas identificadas, se mostra necessário uma evolução dos métodos e a adoção de instrumentos para suprir tal carência.

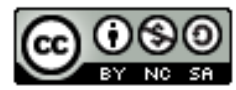


Citação (APA): Rocha, J. T., da, Oliveira, L. A. T., Oliveira, M. C, F., de, Abreu, S. R., de, \& Oliveira, P. W. S., de. (2021). A possibilidade de utilização do sistema WMS para melhoria da gestão de armazenagem: o caso de uma empresa do ramo de construção da zona da mata mineira, 7(5), 166-182.

Atualmente, em todos os setores do mercado e da sociedade, os avanços tecnológicos têm sido muito úteis no auxílio de busca de informação, bem com sistematização de processos e resolução de problemas. Neste sentido, os problemas identificados no estudo de caso podem ter uma solução com base em adoção novas tecnologia voltadas para aas questões pertinentes à gestão da armazenagem.

Trata-se implantação de sistema WMS para auxílio das atividades de estoque. São software que automatiza a gestão de armazém, de forma a oferecer confiabilidade e segurança através de uma gestão de endereçamento, controle de validade e giro dos estoques. O sistema, por intermédio de oferecimento de cadastro pormenorizado e endereçamento dos produtos, é capaz de auxiliar na solução principais problemas encontrados no estudo de caso, pois, será capaz de otimizar recebimento de mercadorias por meio de efetivo controle, planejamento e agendamento; melhorar arranjo de armazenamento, com apontamento de endereçamento e layout de cada setor; melhoria na separação de pedidos e expedição de pedidos que passará a ser célere por consulta de endereçamento, não necessitando de separadores especialistas que conheçam o produto; agilidade na execução de inventários; aumento na confiabilidade e acuracidade de estoque para evitar erros que comprometem a satisfação ao cliente.

Logicamente, por se tratar de implantação de um novo sistema de estoque, esse exigira a contração de empresa especializada e demandará um custo/investimento para obtenção da implantação do sistema e das vantagens a ser alcançadas. Investir em tecnologia é uma necessidade das empresas que desejam se manter ativas no mercado.

Para fins da pesquisa, e como forma de estimar o volume do investimento necessário para obtenção desse recurso pela empresa estudada, foi realizado um orçamento específico, de acordo com a realidade e necessidade da empresa ora em estudo, junto a uma empresa fornecedora de soluções em software de gestão, voltada às melhores práticas de gestão empresarial, com sede em Pato Branco no estado do Paraná. O orçamento realizado prevê a implantação do Sistema WMS, para acesso de até 10 usuários e contempla a Licença de uso, hora técnica de implantação, hora técnica de deslocamento, despesas com deslocamento, estadia e alimentação da equipe, em uma estimativa de necessidade de 290 horas de execução do projeto de implantação, cujo investimento tem perspectiva de aproximadamente $\mathrm{R} \$$ 90.000,00 (noventa mil reais), e a obrigação mensal média no valor $\mathrm{R} \$ 5.000,00$.

A apresentação dos valores antes referidos são uma forma de ilustrar o volume de investimento da tecnologia apontada, apresentados por uma empresa especializada neste ramo de negócios e por se acreditar ser um valor médio de investimento, uma vez que há no mercado muitas outras empresas com a mesma capacidade de oferecimento do serviço.

\section{CONCLUSÃO}

Em um cenário mercadológico marcado pela competitividade, gerir os recurso e processos internos é algo muito relevante para obtenção de sucesso. A ampliação de mercado e o crescimento das organizações trazem às empresas uma proporcional necessidade adequação ao seu volume de negócios, o que reflete na necessidade de expansão para atendimento das novas demandas, principalmente referentes aos pontos de armazenagem e abastecimento de seus 
Citação (APA): Rocha, J. T., da, Oliveira, L. A. T., Oliveira, M. C, F., de, Abreu, S. R., de, \& Oliveira, P. W. S., de. (2021). A possibilidade de utilização do sistema WMS para melhoria da gestão de armazenagem: o caso de uma empresa do ramo de construção da zona da mata mineira, 7(5), 166-182.

pontos de venda. A tecnologia da informação também tem sido de grande valia para a melhoria dos processos logísticos, atuando como ferramenta capaz de otimizar tais processos e melhorar o nível de serviço. Assim a gestão de armazenagem de uma organização é algo de merecedor de atenção uma vez que está é responsável por garantir a disponibilidade de recursos para o atendimento das demandas surgidas.

Considerando a ampliação das atividades, no caso em questão pelas novas vias de comércio, há consequentemente uma série de adequações a serem feitas para suprimento da nova realidade, principalmente quanto as questões de estoque e armazenagem. Como para as novas formas de negócios e comércios o avanço na tecnologia da informação e dos meios tecnológicos podem ser usados como instrumentos de automação e gerencia de processos, sendo úteis para a solução de problemas.

No presente estudo ficou evidenciado que a empresa pesquisada, desde a inserção no $e$ commerce vem tendo bons resultados e ampliando seu nicho de atuação de volume de vendas. Dos bons resultados surgiu a necessidade de ampliação de estoque o que fez potencializar os problemas de armazenagem já existentes. $\mathrm{O}$ estudo levantou as principais falhas e problemas do setor de armazenagem de modo a entender que a empresa em questão, afim de conseguir seu intento de mantença e competitividade no mercado deve reestruturar sua forma e gestão de armazenagem, por meio de planejamento, treinamento de equipe e automação do processo. A proposição realizada para melhoria é a implementação do fermenta WMS (Warehouse Management System), cujas vantagens residem na solução principais problemas encontrado, facilitando todo o processo de operalização de estoque, evitando falhas e promovendo confiabilidade e acuracidade de estoque para evitar erros que comprometem a satisfação ao cliente.

\section{REFERÊNCIAS BIBLIOGRÁFICAS}

Ballou, R. H. (1993). Logística empresarial: transportes, administração de materiais $e$ distribuição física: Atlas.

Ballou, R. H. (2006). Logística empresarial: gerenciamento da cadeia de suprimentos. Porto Alegre: Bookman.

Banzato, E. (n.d). Sistemas de controle e gerenciamento do armazém (wms). Recuperado de https://www.guiadelogistica.com.br/ARTIGO261.htm

Banzato, E., Carillo, E. Jr. Banzato, J. M. , Moura, R, A., \& Rego, S. F. T. (2010) Atualidades na armazenagem. (3a ed.) São Paulo: IMAM.

B2W. (2021). Comércio Eletrônico no Brasil /Institucional / B2W Companhia Digital. Recuperado de https://ri.b2w.digital/institucional/comercioeletronico-no-brasil

Ebit. Webshoppers. (2020) (42 ${ }^{\mathrm{a}}$ ed.). Recuperado de https://myagmexpress.com/downloads/Webshoppers_42.pdf

Euromonitor. (2018). Strategy briefing: Understanding global marketplace trends. Euromonitor International. Recuperado de https://www.euromonitor.com/understandingglobal-marketplace-trends/report

Favoretto, Fábio. (2012). Administração de estoques: diferentes formas de medição da acuracidade. Produto \& Produção, 13(2), 95-105. Recuperado de https://seer.ufrgs.br/ProdutoProducao/article/view/19322/18699 
Citação (APA): Rocha, J. T., da, Oliveira, L. A. T., Oliveira, M. C, F., de, Abreu, S. R., de, \& Oliveira, P. W. S., de. (2021). A possibilidade de utilização do sistema WMS para melhoria da gestão de armazenagem: o caso de uma empresa do ramo de construção da zona da mata mineira, 7(5), 166-182.

Franco, R. S., Maia, L. C. C., \& Souza Filho, R. G. (2020). Avaliação do Nível de Serviço ao Cliente no Contexto do Marketplace da Empresa Alfa. Revista Ciências Administrativas, 26(1), 1-12. http://dx.doi.org/10.5020/2318-0722.2020.26.1.9382

Facchini, E., da Silva, J., \& Leite, V. (2019). Curva abc e estoque de segurança. South American Development Society Journal, 5(13), 73-88. http://dx.doi.org/10.24325/issn.24465763.v5i13p73-88

Brito, I. de, Jr., \& Spejorim, W. (2012). Gestão estratégica de armazenagem. Curitiba: IESDE Brasil S.A..

Kubota, L. C., \& Milani, D. N., (2011). Os efeitos do e-commerce na produtividade das firmas comerciais no Brasil. $\quad$ Recuperado de http://repositorio.ipea.gov.br/bitstream/11058/1441/1/TD 1585.pdf

Kuroda, M. M. (2017). Analise da viabilidade da utilização do software warehouse management system na gestão de armazenagem de produtos e materiais. (Trabalho de Conclusão de Curso - Departamento acadêmico de mecânica). Universidade Tecnológica Federal do Paraná, Cornélio Procópio, PR, Brasil.

Paoleschi, B.. (2014). Estoques e armazenagem. (1. ed.) São Paulo: Erica.

Rodrigues, P. R. A. (2011) Gestão Estratégica da Armazenagem. São Paulo: Aduaneiras.

Rodrigues, E. F., Fernandes A. R., Formigoni, A., Monteiro R., \&Campos, I. P. de A. (2011, outubro). Logística integrada aplicada a um centro de distribuição: Comparativo do desempenho do processo de armazenagem após a implementação de um sistema de gerenciamento de armazém (wms). Simpósio de Excelência em Gestão e Tecnologia-SEGeT, Resende, RJ, Brasil, 8.

Rosa, R. de A. (2015) Gestão de operações e logística. (3a ed.). Departamento de Ciências e administração/UFSC, Brasilia: CAPES: UAB.

Santos, B. T., dos, Lubiana, C. (2017) O uso da curva abc para a tomada de decisão na composição de estoque. Inter-American Journal of Development and Research, 1(1), 62-78. https://doi.org/10.32916/iadrj.v1i1.22

SEBRAE. (2017). Marketplace - Canais de Comercialização. Serviço de Apoio às Micro e Pequenas Empresas. Recuperado de https://www.sebrae.com.br/Sebrae/Portal\%20Sebrae/UFs/CE/Anexos/Cartilha\%20Canais\%20 de\%20Comercializa\%C3\%A7\%C3\%A30\%20-\%20Marketplace.pdf

Soriano, F. F. (2013). Gestão de armazenagem: Uma análise do sistema de gestão wms. (Tese de doutorado).Universidade de São Paulo, São Paulo, SP, Brasil.

Teixeira, T. (2015). Comércio Eletrônico: Conforme o Marco Civil da Internet e a regulamentação do ecommerce no Brasil. São Paulo: Saraiva. 